Original article

\title{
Informing primi and elderly pregnant women about iron sucrose administration for moderate anemia can improve treatment compliance in public health facilities, Kancheepuram health district, Tamil Nadu, India, 2017: A cross-sectional study
}

\author{
Anandan Mohan ${ }^{\text {a,b }}$, Sakthivel Manikandanesan ${ }^{\mathrm{a}}$, Ponnaiah Manickam ${ }^{\text {a,*, }}$ \\ Karumanagounder Kolandaswamy ${ }^{\mathrm{b}}$, Manoj Murhekar ${ }^{\mathrm{a}}$
}

${ }^{\text {a }}$ ICMR-National Institute of Epidemiology, Chennai, Tamil Nadu, India

${ }^{\mathrm{b}}$ Directorate of Public Health and Preventive Medicine, Tamil Nadu, India

\section{A R T I C L E I N F O}

\section{Keywords:}

Compliance

Iron sucrose

Moderate anaemia

Pregnancy

Kancheepuram

\begin{abstract}
A B S T R A C T
Introduction: Tamil Nadu administers intravenous iron sucrose for correcting moderate anaemia among pregnant women (Haemoglobin level $7-8.9 \mathrm{~g} / \mathrm{dl}$ ) based on preliminary studies. We did a cross-sectional study to estimate compliance level and that of factors associated with intravenous iron sucrose treatment for moderate anaemia among pregnant women attending health facilities of Kancheepuram health district, Tamil Nadu, India, 2017. Methods: We needed five pregnant women of 20-30 weeks from 70 clusters (health subcentres) for the assumptions of $64 \%$ compliance, $7 \%$ absolute precision, 95\% Confidence Interval (CI) and a design effect of two. We collected data on knowledge and experience with iron sucrose treatment and reasons for non-compliance. We abstracted haemoglobin levels and administered doses from records. We computed compliance level (\%) with 95\% CI and estimated adjusted odds ratio (AOR) for non-compliance through logistic regression analysis.

Results: The median age of 350 women was 24 years (Range $=22$ to 26). Compliance level to intravenous iron sucrose was 79\% (95\% CI: 73 to 84). Non-compliance was more likely among women aged 25-35 years (AOR: 2.1, 95\% CI: 1.2 to 3.7 ), primi (AOR: 2.2 ' $95 \%$ CI: 1.2 to 3.8 ) and not received treatment information (AOR: 3.1 , 95\% CI: 1.1 to 8.8 ). Major reasons for non-compliance were lack of information about treatment, belief that food was better than injections and that injections could harm the baby.

Conclusions: The compliance to intravenous iron sucrose was insufficient. Providing clear information about intravenous iron sucrose to moderately anaemic pregnant women could increase the compliance to intravenous iron sucrose.
\end{abstract}

\section{Introduction}

Anemia is the most common nutritional deficiency disorder of pregnancy. The World Health Organization (WHO) estimated global prevalence of anaemia among pregnant women of $15-45$ years as $38 \%$ in 2011. ${ }^{1}$ Prevalence of anaemia among pregnant women in South East Asian region (as defined by WHO Regions) is $49 \%$, which is the highest among all the regions in the world. ${ }^{1}$ In India, the prevalence of anaemia among pregnant women is $54 \%$, which is the highest prevalence in the South East Asian region. ${ }^{1}$ Prevalence of anaemia among pregnant women in Tamil Nadu is $44 \% .^{2}$
Anaemia during pregnancy will lead to poor maternal and perinatal outcomes. Anaemic pregnant women have a two-fold increase of preterm deliveries, higher incidences of low birth weight, postpartum haemorrhage and puerperal sepsis. ${ }^{3}$ The babies born to anaemic women have a higher incidence of intensive care unit (NICU) admissions, hyperbilirubinemia, respiratory distress syndrome, neonatal seizures, birth asphyxia and neonatal sepsis. ${ }^{3}$ According to the ministry of women and child development under Government of India, 20\% of maternal deaths in India are due to anaemia and India contributes to half of the global maternal deaths due to anaemia. ${ }^{4}$

Various studies showed that iron sucrose injection is safe and

\footnotetext{
* Corresponding author. Scientist-E \& Faculty, ICMR-National Institute of Epidemiology, R127, Second main road, TNHB, Ayapakkam, Chennai- 600077, India.

E-mail address: manickam@nie.gov.in (P. Manickam).
} 
effective for the treatment of moderate anaemia ${ }^{5}$ (WHO definition: Haemoglobin level 7-9.9 g/dl) during pregnancy and three to four weeks of iron sucrose treatment results in an increase of mean haemoglobin of about $2-3 \mathrm{~g} / \mathrm{dl} .^{6-12}$

The Government of Tamil Nadu has done a pilot study on treatment with iron sucrose for gestational anemia in 2007. The results of the pilot study showed a better increase of haemoglobin level with intravenous iron sucrose than oral iron tablets. ${ }^{13}$ In 2009, National Rural Health Mission Tamil Nadu branch have issued revised guidelines that included treatment for moderate anaemia ( $\mathrm{Hb} 7-8.9 \mathrm{~g} / \mathrm{dl}$ ) during 20-30 weeks of pregnancy with intravenous iron sucrose administration. ${ }^{14}$ As per this guideline, these moderately anaemic pregnant women have to be given four doses of $100 \mathrm{mg}$ iron sucrose in $100 \mathrm{ml}$ of normal saline intravenously over 20-30 min once a day with two to four days interval between each infusion within two weeks. For antenatal mothers infused with iron sucrose, haemoglobin estimation must be done after one month. If the haemoglobin level is still between the 7-8.9 $\mathrm{g} / \mathrm{dl}$ and the duration of pregnancy is less than 30 weeks, two top-up doses of $100 \mathrm{mg}$ of iron sucrose infusion have to be given with two to four days interval between each infusion.

Kancheepuram health unit district is located on the southwest of Chennai, the capital city of Tamil Nadu. Our programme evaluation of high-risk pregnancy in this district in 2016 suggested that among the 250 pregnant women surveyed, $93 \%$ of pregnant women who utilized the public health facilities had anaemia and $19 \%$ had moderate anemia. Our findings suggested that only $64 \%$ of these moderately anaemic pregnant women have completed iron sucrose treatment. ${ }^{15}$

In this context, we conducted a survey to estimate the level of compliance to intravenous iron sucrose for the treatment of moderate anemia and to determine the factors associated with non-compliance to intravenous iron sucrose for the treatment of moderate anemia among pregnant women in 20-30 weeks of pregnancy attending public health facilities of Kancheepuram health unit district, Tamil Nadu, India, 2017.

\section{Methods}

\subsection{Study design}

We did a community-based cross-sectional study.

\subsection{Study participants}

We included the pregnant women who had completed 30 weeks of pregnancy but were moderately anaemic (Haemoglobin level of 7-8.9 g/ dl) during 20-30 weeks of pregnancy and attending public health facilities for antenatal care as study participants. We excluded the pregnant women who were initiated on iron sucrose injection before 30 weeks but currently on treatment, those who were not the resident of Kancheepuram health unit district and the pregnant women less than 18 years.

\subsection{Operational definition}

\subsubsection{Anaemia complicating pregnancy}

We defined "anaemia complicating pregnancy" as haemoglobin level less than $11 \mathrm{~g} / \mathrm{dl}$ in venous blood sample during pregnancy as irrespective of weeks of pregnancy.

\subsubsection{Moderate anaemia}

We defined "moderate anaemia of pregnancy" as haemoglobin level between 7 and $8.9 \mathrm{~g} / \mathrm{dl}$ in venous blood sample during pregnancy irrespective of weeks of pregnancy.

\subsection{Treatment for moderate anemia}

Treatment for moderate anemia during pregnancy was based on the duration of pregnancy. Treatment for the pregnant woman less than 20 weeks of pregnancy was oral iron and folic acid tablets, for the pregnant woman of 20-30 weeks of pregnancy is intravenous iron sucrose injection, and for the pregnant woman more than 30 weeks of pregnancy is blood transfusion.

\subsection{Intravenous iron sucrose treatment}

Intravenous iron sucrose treatment refers to the intravenous infusion of $100 \mathrm{mg}$ Iron sucrose in $100 \mathrm{ml}$ of normal saline for 20-30 min once a day for four days with 2-4 days of interval between each infusion within a period of two weeks.

\subsection{Compliance to intravenous iron sucrose treatment}

A moderately anaemic pregnant woman who has completed four of iron sucrose injections as per guidelines is said to be compliant to treatment.

\subsection{Non-compliance to intravenous iron sucrose treatment}

A moderately anaemic pregnant woman who has not completed four doses of iron sucrose injections is said to be non-compliant, regardless of the number of doses received from zero to three.

\subsection{Sampling procedure}

We used cluster sampling method. The primary sampling unit was the health sub-centres (HSC). We used probability proportionate to the population size of pregnant women (more than 30 weeks) of each HSC through linear systematic sampling for cluster selection. In the HSCs, a line-list of pregnant women with anemia status was not available. Hence, a trained village health nurse serially selected the required number of study participants from each HSC.

\subsection{Sample size}

We needed to select five pregnant women each from 70 clusters (HSCs) based on the assumptions of $64 \%$ compliance to iron sucrose treatment among moderately anaemic pregnant women $(n=3373)$ in the district from $192 \mathrm{HSCs}$, with 7\% absolute precision, design effect of two and 95\% confidence interval (CI). There were no line lists maintained for pregnant women with anaemia along with severity grade. Thus, we trained village health nurses to select five study participants, using the operation definition for moderate anaemia, consecutively among the pregnant women visiting their respective health facility.

\subsection{Data collection methods and tools}

The principal investigator and trained investigators interviewed pregnant women with a structured questionnaire in the local language Tamil at the community level. We collected data on socio-demographiceconomic, past experience with iron sucrose, accessibility-related details such as easy access to primary health centres and availability of transport facilities, pregnancy details, awareness about anaemia, health care provider's interactions with anaemic women regarding their anaemia status, plan of treatment and the reasons for non-compliance. We reviewed records available with the pregnant women (mother and child protection card). From the record, we collected data on last menstrual period (LMP), expected date of delivery (EDD), haemoglobin level for three-time periods (14-16 weeks, 20-24 weeks, 26-30 weeks), height, weight and treatment with iron sucrose and the number of doses received. The principal investigator cross-verified five percent of the interviews for quality assurance. 
Table 1

Socio-demographic characteristics of the study participants in the survey of noncompliance to intravenous iron sucrose administration for moderate anemia among pregnant women $(\mathrm{N}=350)$, Kancheepuram health district, Tamil Nadu, India, 2016-17.

\begin{tabular}{lll}
\hline Socio-demographic characteristics & $\mathrm{n}$ & $\%$ \\
\hline Median age (in years) [Interquartile range] & $24[22,26]$ & \\
Multigravida & 204 & 58 \\
Hindu religion & 325 & 93 \\
Scheduled caste and tribal community & 155 & 44 \\
Illiterate & 15 & 4 \\
House wife & 288 & 82 \\
\hline
\end{tabular}

\subsection{Data analysis}

We calculated descriptive statistics to describe the characteristics of the study participants. We estimated the level of compliance to intravenous level with $95 \%$ CI. We compared the frequency of exposures among non-compliant and compliant for intravenous iron sucrose administration and calculated crude prevalence odds ratios (POR) and 95\% CI using binary logistic regression analysis. We examined the exposures for third factors. We computed adjusted ORs (AOR) and 95\% CI after adjusting for confounders using multivariable logistic regression to identify variables independently associated with non-compliance to intravenous iron sucrose administration. We calculated the fraction of non-compliance attributable to the identified risk factors in the population [Population attributable risk (PAR)] using the classical formula: the proportion of particular risk factor in the population multiplied by the attributable fraction among exposed (1-1/odds ratio). We entered and analysed the data using Epi Info software (version 7.2).

\subsection{Human participant protection}

We obtained approval from the Institutional Ethics Committee of ICMR School of Public Health, ICMR-National Institute of Epidemiology, Chennai and permission from the Tamil Nadu State Directorate of Public Health and Preventive Medicine and District Director of Health Services. We obtained informed written consent from all the participants in the local language. We maintained the confidentiality of the collected data by removing identifiers.
Table 2

Factors associated with non-compliance to administration of intravenous iron sucrose for moderately anemic pregnant women attending public health facilities $(\mathrm{N}=350)$ in Kancheepuram health district, Tamil Nadu, India, 2016-17.

\begin{tabular}{|c|c|c|c|c|c|c|}
\hline \multirow[t]{3}{*}{ Factors } & \multirow{2}{*}{\multicolumn{2}{|c|}{$\begin{array}{l}\text { Among } \\
\text { non- } \\
\text { compliant } \\
(\mathrm{n}=74)\end{array}$}} & \multirow{2}{*}{\multicolumn{2}{|c|}{$\begin{array}{l}\text { Among } \\
\text { compliant } \\
(\mathrm{n}=276)\end{array}$}} & \multicolumn{2}{|c|}{ Crude Odds Ratio } \\
\hline & & & & & \multirow[t]{2}{*}{ Estimate } & \multirow[t]{2}{*}{$95 \% \mathrm{CI}$} \\
\hline & \# & $\%$ & \# & $\%$ & & \\
\hline Aged $25-35$ years & 39 & 53 & 115 & 42 & 1.6 & $0.9-2.6$ \\
\hline $\begin{array}{l}\text { Belonging to schedule caste } \\
\text { and tribal community }\end{array}$ & 36 & 49 & 119 & 43 & 1.3 & $0.7-2.1$ \\
\hline $\begin{array}{l}\text { Illiterate or educated up to } \\
\text { middle school }\end{array}$ & 21 & 28 & 92 & 33 & 1.3 & $0.7-2.2$ \\
\hline Employed & 16 & 22 & 46 & 17 & 1.4 & $0.7-2.6$ \\
\hline $\begin{array}{l}\text { Did not have iron sucrose in } \\
\text { the previous pregnancies }\end{array}$ & $29^{\mathrm{a}}$ & 81 & $130^{\mathrm{b}}$ & 77 & 1.2 & $0.5-3$ \\
\hline $\begin{array}{l}\text { Had reactions during } \\
\text { treatment }\end{array}$ & $14^{c}$ & 40 & $27^{\mathrm{d}}$ & 10 & 6.1 & $2.8-13.8$ \\
\hline Primigravida & 38 & 51 & 108 & 39 & 1.6 & $1-2.8$ \\
\hline $\begin{array}{l}\text { Health facility located } \\
\text { beyond } 5 \mathrm{~km} \text { from home }\end{array}$ & 39 & 53 & 139 & 50 & 1.1 & $0.7-1.8$ \\
\hline $\begin{array}{l}\text { Waiting time for transport } \\
\text { more than } 2 \mathrm{~h}\end{array}$ & 18 & 24 & 44 & 16 & 1.7 & $0.9-3.2$ \\
\hline $\begin{array}{l}\text { Medical officer not present } \\
\text { during visit to health } \\
\text { facility }\end{array}$ & 1 & 1 & 2 & 1 & 1.9 & $0.2-20.1$ \\
\hline $\begin{array}{l}\text { Non-availability of iron } \\
\text { sucrose injection }\end{array}$ & 6 & 8 & 2 & 1 & 12.1 & $2.4-61.2$ \\
\hline $\begin{array}{l}\text { Waiting time to get injection } \\
\text { more than } 1 \mathrm{~h}\end{array}$ & 5 & 14 & 24 & 9 & 1.8 & $0.6-4.9$ \\
\hline Unaware of anaemia & 10 & 14 & 8 & 3 & 5.2 & $2-13.8$ \\
\hline $\begin{array}{l}\text { Unaware of iron sucrose } \\
\text { treatment }\end{array}$ & 26 & 35 & 11 & 4 & 13.1 & $6-28.2$ \\
\hline
\end{tabular}

\section{Results}

\subsection{Profile of study participants}

We interviewed 350 moderately anaemic pregnant women [Median age (range): 24 years (22-26) years]. Most of them (93\%) belonged to the Hindu religion, and $44 \%$ belonged to scheduled caste and tribal community. Four percent were illiterate, and $82 \%$ were housewives (Table 1).

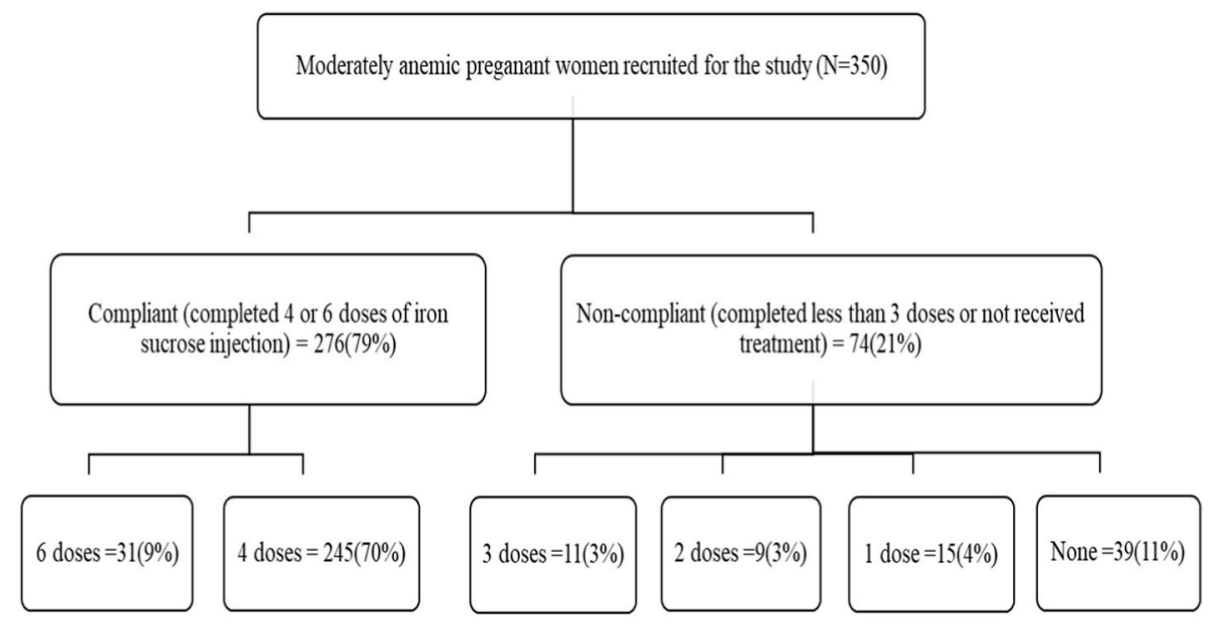

Fig. 1. Compliance level among the moderately anaemic pregnant women $(\mathrm{N}=350)$ to intravenous iron sucrose treatment, Kancheepuram health unit district, Tamil Nadu, India, 2016-17. 
Table 3

Factors associated with non-compliance to administration of intravenous iron sucrose for moderately anemic pregnant women attending public health facilities of Kancheepuram health district, Tamil Nadu, India, 2016-17.

\begin{tabular}{llll}
\hline Factors & Crude OR & \multicolumn{2}{l}{ Adjusted OR } \\
\cline { 3 - 4 } & & Estimate & 95\% CI \\
\hline Aged 25-35 years $^{\mathrm{a}}$ & 1.6 & 2.1 & $1.2-3.7$ \\
Primigravida $^{\mathrm{b}}$ & 1.6 & 2.2 & $1.2-3.8$ \\
Not informed about iron sucrose treatment $^{\mathrm{c}}$ & 13.1 & 11.5 & $5.2-25.1$ \\
\hline
\end{tabular}

a Adjusted with gravida.

b Adjusted with age.

c Adjusted with non-availability of iron sucrose.

Slightly more than half of these women (51\%) resided $5 \mathrm{~km}$ away from the health facilities, and the frequency of transport facility from their residence to the health facility and vice versa was less than $1 \mathrm{~h}$. Fifty-eight percent of them were multigravida, and among them, one fourth have received iron sucrose in their previous pregnancies. Among the 350 study participants who were prescribed with iron sucrose injection, $89 \%$ (311 pregnant women) had received at least one dose of the injection during the current pregnancy. Among these 311 women, 41 (13.2\%) had drug reactions during treatment. Majority (95\%) of the participants were aware that they were suffering from anaemia and were informed about four doses of iron sucrose treatment (89\%). Most of these women reported that medical officer was available $(99.1 \%)$ and iron sucrose was in stock (98.9\%) when they had visited the facility for iron sucrose treatment. The waiting period was less than $1 \mathrm{~h}$ for the majority (91\%) of women who received the injection.

\subsection{Compliance to iron sucrose treatment}

Of the 350 women surveyed, 276 (79\%) complied with iron sucrose treatment (95\% CI: 73-84) (Design effect $=1.9$ ). Of these 276 women, $31(8.9 \%)$ received six doses. Among the $74(21 \%)$ women who were non-compliant, 39 (11.1\%) did not receive even one dose (Fig. 1).

Factors associated with non-compliance to intravenous iron sucrose treatment among the moderately anaemic pregnant women:
We identified that primigravida (OR 1.6, 95\% CI: 1-2.8, PAR\%: $15.6 \%)$, pregnant women who had drug reactions during treatment (OR: 6.1, 95\% CI: 2.8-13.5, PAR\%: 11.5\%), non-availability of iron sucrose during their visit to the facility (OR: $12.1,95 \%$ CI: $2.4-61.2$, PAR\%: $0.02 \%$ ), unaware of their moderate anaemia status (OR: $5.2,95 \% \mathrm{CI}$ : 2-13.8, PAR\%: 0.04\%) and not informed about intravenous iron sucrose treatment (OR: 13.1, 95\% CI: 6-28.2, PAR\%: 0.1\%) were factors associated with non-compliance to intravenous iron sucrose treatment (Table 2). We selected, "primigravida", "unaware of anaemia", and "not informed about intravenous iron sucrose injection" as parameters for multivariable analysis. In the multivariable analysis, we identified that primigravida [vs. Multigravida] (AOR: $2.2,95 \%$ CI: $1.2-3.8$, PAR\%: $22.7 \%$ ) and not informed about the iron sucrose treatment (AOR: 11.5, 95\% CI: 5.2-25.1, PAR\%: 0.1\%) were independently associated with non-compliance to iron sucrose treatment (Table 3 ).

Self-reported reasons for non-compliance to iron sucrose treatment:

The primary reasons for non-compliance reported by those women who received one to three doses of intravenous iron sucrose injections were drug reactions (37\%), followed by completion of treatment in private facilities (26\%) and the belief that diet was better to improve the blood haemoglobin level than injections (26\%). The major reasons among those who did not undergo the treatment were, not informed about iron sucrose treatment by the health providers (44\%), followed by completion in private facilities (31\%) and the belief that diet was better to improve the blood haemoglobin level than injections (23\%) (Fig. 2).

\section{Discussion}

We surveyed moderately anaemic women attending public health facilities in Kancheepuram health district, Tamil Nadu. Over threefourth women were compliant to the treatment of moderate anemia with iron sucrose injection. We identified that primigravida, drug reactions during treatment, non-availability of iron sucrose injections and not informed about treatment were significantly associated with noncompliance to iron sucrose treatment.

Compliance to intravenous iron sucrose in our study was $79 \%$. It was higher than that found in other studies conducted in various parts of

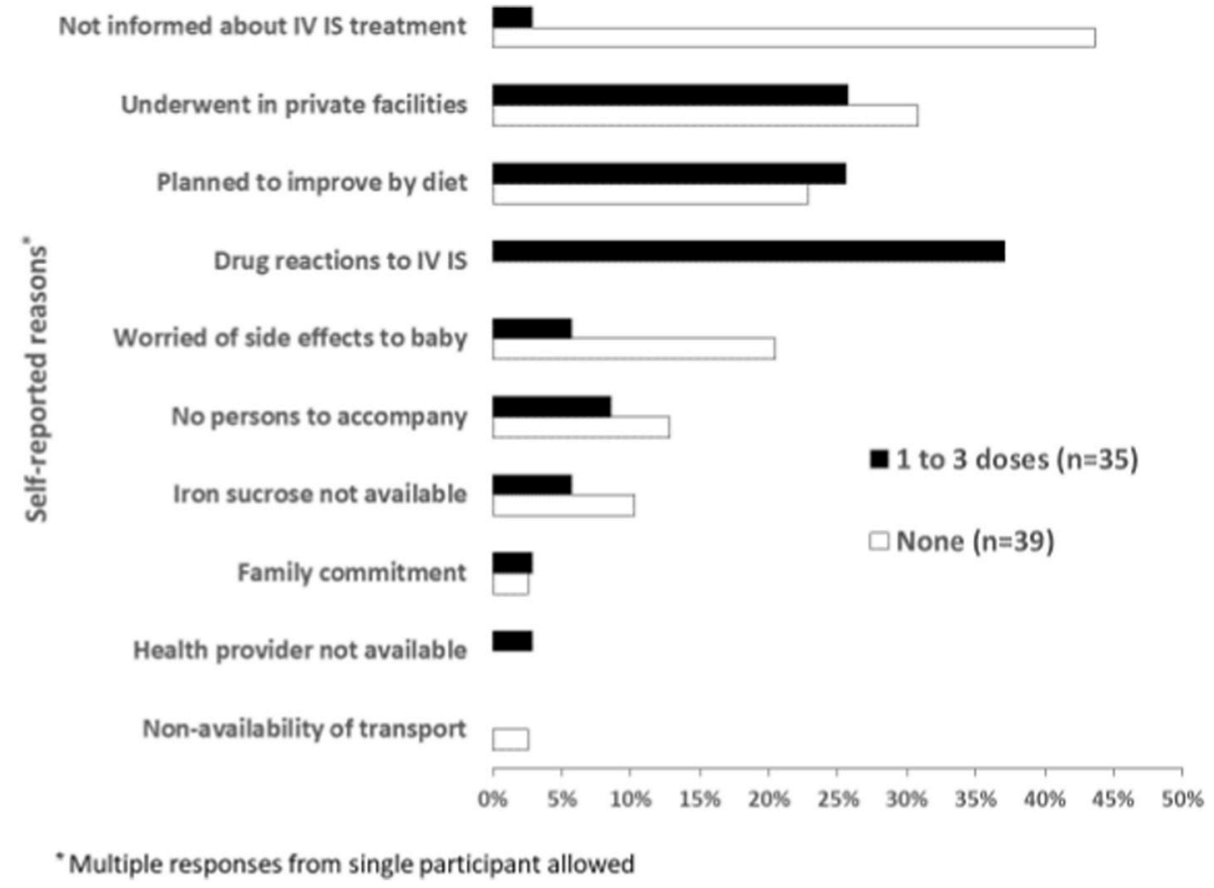

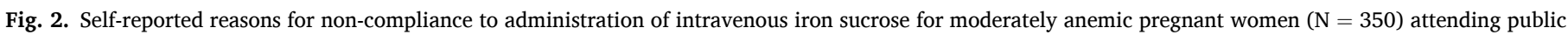
health facilities of Kancheepuram health district, Tamil Nadu, India, 2016-17. 
India, where the compliance to oral tablets was between $62 \%$ and $65 \%{ }^{16,17}$ The reason for this difference could be that our study participants were moderately anaemic. Hence they may be more symptomatic than participants in other studies which included mild anaemic pregnant women as well. Compliance to oral iron tablets was $66 \%$ according to a survey in Nigeria, which was lesser than what we estimated in our study. ${ }^{18}$ This could be because our study participants were provided with the drugs free of cost. Primigravida women were more likely to be non-compliant, which is similar to a study done in South India with similar socio-demographic conditions. ${ }^{17}$ In our study, when pregnant women were not informed about intravenous iron sucrose, they were more likely to be non-compliant. This finding was similar to that reported in studies from India and Africa. ${ }^{16,19}$ We have compared the compliance of oral iron supplements with intravenous iron supplements, so the comparison may not be viable. Further studies are needed to increase the generalizability of these findings.

Our study has few limitations. Firstly, we anticipate that selection bias could have operated in two ways. We trained health workers to identify the anaemic status of pregnant women and then select the study participants. There is a possibility that the health workers might have enrolled study participant whom they thought would be more compliant to the injection. Hence, this could have led to an over-estimation of compliance. Secondly, we had assumed that women who had reported having treatment in private facilities as non-compliant $(n=21 ; 6 \%)$. However, we believe that this could have compensated for the overestimate from the previous bias introduced by health workers to a certain extent. Despite these limitations, our study findings can be generalizable in the context of women seeking antenatal care in the district. The key strength of the study is that within a district health system context, we could answer the question that emerged from an earlier evaluation of high-risk pregnancy. ${ }^{15}$ Through the evaluation, we did identify that poor compliance to iron sucrose treatment among moderately anemic pregnant women was an important problem. In the present study, we could pursue the reasons for non-compliance and generate evidence for the health system to target specific groups to improve compliance levels.

Based on our findings, we concluded that over three-fourth of the moderately anaemic pregnant women were compliant to intravenous iron sucrose treatment in public health facilities of Kancheepuram health unit district. Primi women of 25-35 years who received no information about the intravenous iron sucrose treatment were noncompliant.

To improve compliance to intravenous iron sucrose treatment for managing moderate anemia among pregnant women attending public health facilities, we recommend providing clear information with counselling about the intravenous iron sucrose treatment mainly targeting primi aged $25-35$ years.

\section{acknowledgements}

We thank the Deputy Director of Health Services, Kancheepuram,
Tamil Nadu for prioritizing and guiding this research work and the entire district public health workforce belonging to the Tamil Nadu Directorate of Public Health and Preventive Medicine for their support.

\section{References}

1 World Health Organization. The global prevalence of anaemia in 2011 [cited 2020 November 27]. Available from: https://apps.who.int/iris/bitstream/handle/10665/ 177094/9789241564960_eng.pdf? sequence=1\&isAllowed=y ; 2011, 48.

2 International Institute for Population Sciences. National family health survey-4. State fact sheet Tamil Nadu 2015-16. . Available from: http://rchiips.org/nfhs/factsh eet_NFHS-4.shtml ; 2015, 4.

3 Bangal VB, Kunal A, Ketki B, Tuse H. Study of maternal and perinatal outcome in moderate to severe degree iron deficiency anaemia in rural community. Int $J$ Biomed Adv Res. 2016;7(2):88-93.

4 Ministry of Women and Child Development, Government of India. Report on Micronutrient Deficiencies. New Delhi: Ministry of women and child development, Government of India; 2008 [cited 2016 September 27]. Available from: http://wcd. nic.in/Schemes/research/nti1947/7.11.1\%20Anaemia\%20deficiency.doc6.2.08\% 20pr.pdf.

5 World Health Organization. WHO. Haemoglobin Concentrations for the Diagnosis of Anaemia and Assessment of Severity. Vitamin and Mineral Nutrition Information System. Geneva: World Health Organization; 2011 (WHO/NMH/NHD/MNM/11.1) http://www.who.int/vmnis/indicators/haemoglobin. pdf.

6 Batar A, Salvi A, Saini L, Agarwal S, Rajoria L, Mital P. Maternal and perinatal outcome in pregnancy with severe anaemia. Int J Biomed Adv Res. 2015 Aug 30;6(8): 611-616.

7 Harminder Singh Dk. Singh I. Anaemia. Pregnancy - how effective is intravenous iron sucrose therapy? International Journal of Recent Scientific. July 2015;6(7):4900-4907.

8 Thakor N, Bhagora S, Asari U, Kharadi A, Pandor J, Prajapati D. Effect of intravenous iron sucrose therapy for moderate-to-severe anemia in pregnancy: a longitudinal study. Int J Med Sci Publ Health. 2015 Jan 1;4:11-14.

9 Dubey S, Suri V, Aggarawal N, Das R. Is it safe to use intravenous iron sucrose during pregnancy? A randomized controlled trial. Int J Reprod Contracept Obstet Gynecol. 2013;2:544-549.

10 Tembhare A, Shelke S, Varma PS. Efficacy of parenteral iron sucrose in treatment of pregnancy associated iron deficiency anemia with special reference to body iron stores. Int J Biomed Res. 2015;6:927-932.

11 Aggarwal RS, Mishra VV, Panchal NA, Patel NH, Deshchougule VV, Jasani AF. Evaluation of iron sucrose and oral iron in management of iron deficiency anaemia in pregnancy. International Journal of Community Medicine. 2012;3(1):55-60.

12 Shrivastava D, Inamdar S, Bhute S, Singh A. Effectiveness of intravenous iron sucrose in management of iron-deficient anemia of pregnancy at rural hospital set up. J Obstet Gynaecol India. 2012;62(2):154-157.

13 Centre for innovations in public systems. Use of IV iron sucrose injection for severe gestational anaemia management, Tamil Nadu. Hyderabad, India: CIPS [cited 2020 November 27]. Available from: http://www.cips.org.in/documents/2012/IV-IronSucrose-Case-study-for-Gestational-Anaemia-Management.pdf; 2009.

14 National Rural Health Mission. Guidelines for prevention of iron deficiency anaemia: NRHM, Tamil Nadu. November 27]. Available from: http://www.nrhmtn.gov.in/ guideline/RGPMA.pdf ; 2020, 1-12.

15 Mohan A, Manickam P. High risk pregnancy programme evaluation, Kancheepuram health unit district, Tamil Nadu, India. MPH field projects bound. 2016;8(11):14, 14.

16 Pal PP, Sharma S, Sarkar TK, Mitra P. Iron and folic acid consumption by the antenatal mothers in a rural area of India in 2010. Int J Prev Med. 2013 Oct;4(10):1213.

17 Mithra P, Unnikrishnan B, Rekha T, et al. Compliance with iron-folic acid (IFA) therapy among pregnant women in an urban area of south India. Afr Health Sci. 2014; 14(1):255-260.

18 Ugwu EO, Olibe AO, Obi SN, Ugwu AO. Determinants of compliance to iron supplementation among pregnant women in Enugu, Southeastern Nigeria. Niger J Clin Pract. 2014;17(5):608-612.

19 Gebremedhin S, Samuel A, Mamo G, Moges T, Assefa T. Coverage, compliance and factors associated with utilization of iron supplementation during pregnancy in eight rural districts of Ethiopia: a cross-sectional study. BMC Publ Health. 2014 Jun 14;14 (1):607. 